Pacific Journal of Mathematics

A NONNORMAL BLASCHKE-QUOTIENT 


\title{
A NONNORMAL BLASCHKE-QUOTIENT
}

\author{
JoSEPH A. Cima
}

\begin{abstract}
We shall call the meromorphic functions of the form $F(z)=$ $B_{1}(z) / B_{2}(z)$ Blaschke-quotients, where $B_{1}(z)$ and $B_{2}(z)$ are Blaschke products in $|z|<1$ with zeros at $\left\{a_{n}\right\}$ and $\left\{b_{k}\right\}$ respectively. Although there is a characterization of meromorphic functions which are normal there is no characterization of the Blaschkequotients which are normal in terms of the non-Euclidean (hyperbolic) distances between the zeros $\left\{a_{n}\right\}$ and $\left\{b_{k}\right\}$. In this paper we show by construction that even if the zeros of a Blaschke-quotient are separated by a positive non-Euclidean distance the Blaschke-quotient need not be normal.
\end{abstract}

We shall be concerned in this paper with the boundary behavior of meromorphic functions. The concept of a normal function was introduced by K. Noshiro in [2]. Several properties of normal meromorphic functions are developed in a paper of $\mathrm{O}$. Lehto and $\mathrm{K}$. I. Virtanen [2]. Their definition of a normal meromorphic function is:

Definition A meromorphic function $f(z)$ is called normal in a simply-connected domain $G$ if the family $\{f(S(z))\}$ is normal in $G$ (in the sense of Montel), where $z^{\prime}=S(z)$ denotes an arbitrary one-to-one conformal mapping of $G$ onto itself.

In the same paper they gave the following characterization of a normal meromorphic function:

THEOREM 1. A nonconstant function $f(z)$, meromorphic in a domain $G$, is normal if and only if

$$
\rho(f(z))|d z| \leqq C d \sigma(z)
$$

at every point of $G . \rho(f)$ is the spherical derivative of $f, d \sigma$ is the hyperbolic element of length and $C$ is an absolute constant.

The class of normal functions includes the bounded functions, schlicht functions and functions omitting three values. Moreover, it is known that the class of normal functions interselects the class of functions of bounded characteristic. Functions of bounded characteristic. Functions of bounded characteristic have the following form

$$
F(z)=e^{i \lambda} \frac{B_{1}(z)}{B_{2}(z)} \exp \left(\frac{1}{2 \pi} \int_{0}^{2 \pi} \frac{e^{i \theta}+z}{e^{i \theta}-z} d \psi(\theta)\right)
$$

Received April 17, 1964 and in revised form August 3, 1964. 
$\psi(\theta)$ is a function of bounded variation, $\lambda$ is real and the $B_{i}(z)$ are infinite products.

$$
\begin{aligned}
B\left(z, a_{n}\right)= & B_{1}(z)=\prod_{n=1}^{\infty} \frac{\left|a_{n}\right|}{a_{n}}\left(\frac{a_{n}-z}{1-\bar{a}_{n} z}\right), \\
& \sum_{n=1}^{\infty}\left(1-\left|a_{n}\right|\right)<\infty .
\end{aligned}
$$

For brevity we refer to a quotient of the form $B_{1}(z) / B_{2}(z)$ as a Blaschke-quotient. There are functions which are normal which are not of bounded characteristic and functions of bounded characteristic which are not normal. In particular F. Bagemihl and W. Seidel [1] have constructed a holomorphic function of bounded characteristic which is not normal.

If $z_{1}$ and $z_{2}$ are two points of the unit disk $D=\{z|| z \mid<1\}$, the non-Euclidean (hyperbolic) distance between $z_{1}$ and $z_{2}$ is given by the formula

$$
\rho\left(z_{1}, z_{2}\right)=\frac{1}{2} \log \left(\frac{1+|h|}{1-|h|}\right), \quad h=\frac{z_{1}-z_{2}}{1-\bar{z}_{1} z_{2}}
$$

The following theorems of F. Bagemihl and W. Seidel [1] show that the non-Euclidean metric is in a sense a natural one for discussing the boundary behavior of a normal function.

THEOREM 2. Let $\left\{z_{n}\right\}$ be a sequence of points in $D=\{z|| z \mid<1\}$ which converges to a point $\zeta \in C=\{z|| z \mid=1\}$ and is such that lim $\rho\left(z_{n}, z_{n+1}\right)=0$ as $n \rightarrow \infty$, and let $f(z)$ be a normal meromorphic function in $D$ for which $\lim f\left(z_{n}\right)=c$ as $n \rightarrow \infty$, where $c$ is finite or infinite. Then $f(z)$ has the angular limit $c$ at $\zeta$.

TheORem 3. Let $\left\{z_{n}\right\}$ be a sequence of points in $D=\{|z|<1\}$ for which $\left|z_{n}\right| \rightarrow 1$ and $f(z)$ is a normal, meromorphic function in $D$ such that $\lim f\left(z_{n}\right)=C$. If $\left\{z_{n}^{\prime}\right\}$ denotes any sequence of points in $D$ for which $\lim _{n \rightarrow \infty} \rho\left(z_{n}, z_{n}^{\prime}\right)=0$, then also $\lim _{n \rightarrow \infty} f\left(z_{n}^{\prime}\right)=C$.

One problem remaining in the study of normal functions is to determine those Blaschke-quotients which are normal. That is, if $F(z)=B_{1}(z) / B_{2}(z)=B_{1}\left(z ; a_{n}\right) / B_{2}\left(z ; b_{n}\right)$, to determine conditions on the non-Euclidean distances between the zeros of $B_{1}$ and $B_{2}$ which will make $F$ normal. We note a few immediate results and then construct an example of a Blaschke-quotient such that the zeros of $B_{1}$ and those of $B_{2}$ are separated by a positive non-Euclidean distance and such that $B_{1}(z) / B_{2}(z)$ is not normal. 
2. The construction. The first comment to be made is that a Blaschke-product has radial limits a.e. That is, $\lim B\left(r e^{i \theta}\right), r \rightarrow 1$, exists and equals a complex uni-modular number $e^{i \varphi}$ [3]. The only singularities of $B(z)=B\left(z ; a_{n}\right)$ in $|z| \leqq 1$ are those points $z_{0},\left|z_{0}\right|=1$, such that there is a subsequence $\left\{a_{n_{k}}\right\}$ of the zeros of $B\left(z ; a_{n}\right)$ with $a_{n_{k}} \rightarrow z_{0}$ as $k \rightarrow \infty$. If we denote by $A\left(a_{n}\right)$ the set of limit points of the set $\left\{a_{n}\right\}$, then we have the following:

Lemma 1. Let $F(z)=B_{1}(z) / B_{2}(z)=B_{1}\left(z ; a_{n}\right) / B_{2}\left(z ; b_{n}\right)$. Then if $A\left(a_{n}\right) \cap A\left(b_{n}\right)$ is empty, $F$ is normal.

Proof. The condition of Theorem 1 for $F=B_{1} / B_{2}$ with domain the unit disk is

$$
\rho(F(z))|d z|=\frac{\left|B_{1}(z) B_{2}^{\prime}(z)-B_{1}^{\prime}(z) B_{2}(z)\right|}{\left|B_{1}(z)\right|^{2}+\left|B_{2}(z)\right|^{2}}|d z| \leqq \frac{C|d z|}{\left(1-|z|^{2}\right)} .
$$

For $P=e^{i \varphi}$ it suffices to show

$$
\varlimsup_{\substack{z \rightarrow P \\|z|<1}} \frac{\left|B_{1}(z) B_{2}^{\prime}(z)-B_{1}^{\prime}(z) B_{2}(z)\right|}{\left|B_{1}(z)\right|^{2}+\left.B_{2}(z)\right|^{2}}\left(1-|z|^{2}\right)<\infty .
$$

Now

$$
\begin{gathered}
\frac{\left|B_{1}(z) B_{2}^{\prime}(z)-B_{1}^{\prime}(z) B_{2}(z)\right|\left(1-|z|^{2}\right)}{\left|B_{1}(z)\right|^{2}+\left|B_{2}(z)\right|^{2}} \\
\leqq \\
\frac{\left|B_{2}^{\prime}(z)\right|\left(1-|z|^{2}\right)+\left|B_{1}^{\prime}(z)\right|\left(1-|z|^{2}\right)}{\left|B_{1}(z)\right|^{2}+\left|B_{2}(z)\right|^{2}} .
\end{gathered}
$$

The lemma follows from the fact that

$$
\lim _{\substack{z \rightarrow P \\|z|<1}}\left(\left|B_{1}(z)\right|^{2}+\left.B_{2}(z)\right|^{2}\right) \geqq 1
$$

and a result of W. Seidel and J. L. Walsh [5] which states that $\left|B_{\imath}^{\prime}(z)\right|(1-|z|)$ is bounded for $|z|<1$.

The following lemma is a restatement of Theorem 3 .

Lemma 2. If $F(z)=B_{1}\left(z ; a_{n}\right) / B_{2}\left(z ; b_{n}\right)$, with $\left\{a_{n}\right\}$ and $\left\{b_{n}\right)$ disjoint, and if there exist subsequences $\left\{a_{n_{k}}\right\}$ and $\left\{b_{n_{k}}\right\}$, with $\rho\left(a_{n_{k}}, b_{n_{k}}\right)$ tending to zero as $k \rightarrow \infty$, then $F$ is not normal.

We turn now to the example.

THEOREM 4. There exists a Blaschke-quotient $F(z)=B_{1}\left(z ; a_{n}\right) / B_{2}\left(z ; b_{n}\right)$ with $\rho\left(a_{n}, b_{k}\right) \geqq \delta_{1}>0$ for all positive integers $n$ and $k$ such that $F$ is not normal. 
Proof. The construction proceeds as follows. We exhibit a Blaschke-product $B_{2}\left(z ; b_{n}\right)$ whose zeros lie in an angle at $z=1$ and which tends to zero in angular approach to 1 . We can then construct $B_{1}\left(z ; a_{n}\right)$ such that the zeros $\left\{a_{n}\right\}$ tend to 1 and have the property expressed in the theorem. $B_{1}(z)$ has the additional property that there is a nontangential path $\Gamma$ such that $\lim B_{1}(z)$ for $z$ on $\Gamma$ is positive. This implies

$$
\lim _{\substack{z \rightarrow 1 \\ z \in \Gamma}} \frac{B_{1}(z)}{B_{2}(z)}=\lim _{\substack{z \rightarrow 1 \\ z \in \Gamma}} \frac{B_{1}\left(z ; a_{n}\right)}{B_{2}\left(z ; b_{n}\right)}=\infty
$$

whereas $B_{1}\left(a_{n}\right) / B_{2}\left(a_{n}\right)=0$. Applying Theorem 2 , we see that $F$ cannot be normal.

First define $B_{2}$ as follows:

$$
B_{2}\left(z ; b_{n}\right)=B_{2}\left(z ; 1-\frac{1}{n_{2}}=\prod_{n=1}^{\infty} \frac{\left(1-\frac{1}{n^{2}}\right)-z}{1-\left(1-\frac{1}{n^{2}}\right) z}\right.
$$

$B_{2}(z)$ is well defined and holomorphic in $|z|<1$. The function $\rho_{n}$,

$$
\rho_{n}=\rho\left(b_{n}, b_{n+1}\right)=\frac{1}{2} \log \left(\frac{1+\left|h_{n}\right|}{1-\left|h_{n}\right|}\right)
$$

where

$$
\left|h_{n}\right|=\left|\frac{\left(1-\frac{1}{n^{2}}\right)-\left(1-\frac{1}{(n+1)^{2}}\right)}{1-\left(1-\frac{1}{n^{2}}\right)\left(1-\frac{1}{(n+1)^{2}}\right)}\right|=\frac{2 n+1}{2 n^{2}+2 n}
$$

tends to zero as $n \rightarrow \infty$. Theorem 2 shows that $B_{2}$ has angular limit zero at $z=1$.

For the remainder of the construction we find it useful to do some of the work in a half plane. The linear transformation $T$,

$$
T(z)=i\left(\frac{1+z}{1-z}\right)=\omega=u+i v
$$

maps $|z|<1$ onto $v>0$, preserving the non-Euclidean metric. The point $z=1$ corresponds to $\omega=\infty$. As a nontangential path tending to infinity we choose the hypercycle $u=v, v>0$. This curve has fixed non-Euclidean distance $1 / 2 \log (\sqrt{2}+1)$ from $u=0, v>0$. Select points $\alpha_{n}^{\prime}$ as follows:

$$
a_{n}^{\prime}=\alpha_{n} e^{i \pi / 4}=\left(2 e^{n}-1\right) e^{i \pi / 4} .
$$


The corresponding points $a_{n}$ of $|z|<1$ are

$$
T^{-1}\left(a_{n}^{\prime}\right)=a_{n}=\frac{a_{n}^{\prime}-i}{a_{n}^{\prime}+i} .
$$

Define $B_{1}(z)$ by using the points $\left\{a_{n}\right\}$ as the zeros of $B_{1}(z)$. To show $B_{1}(z)$ is well defined, it suffices to show $\sum_{n=1}^{\infty}\left(1-\left|a_{n}\right|\right)<\infty$.

$$
\sum_{n=1}\left(1\left|a_{n}\right|\right)=\sum_{n=1}^{\infty}\left(1-\frac{\left(\alpha_{n}^{2}+1\right)-\sqrt{2} \alpha_{n}}{\left[\left(a_{n}+1\right)^{2}-2 \alpha_{n}^{2}\right]^{1 / 2}}\right) \leqq \sum_{n=1}^{\infty} \frac{\sqrt{2}}{\alpha_{n}} .
$$

This last series has terms which are order of magnitude of $e^{-n}$ and so converges.

We note that the curve $u=v$ maps under $T^{-1}$ into a hypercycle $h_{\alpha}$ having a fixed non-Euclidean distance from the real axis. It also forms the fixed angle $\pi / 4$ with the real axis at $z=1$. Thus the zeros of $B_{1}(z)$ and those of $B_{2}(z)$ are separated by a positive non-Euclidean distance.

In the plane $v>0, B_{1}(z)$ has the form

$$
B_{1}(z)=B_{1}\left(T^{-1}(\omega)\right)=\pi_{1}(\omega)=\prod_{\nu=1}^{\infty} e^{i p_{n}}\left(\frac{\omega-a_{n}^{\prime}}{\bar{a}_{n}^{\prime}-\omega}\right)
$$

where $p_{n}$ is real. Now select points $i \beta_{k}=i\left(2 k^{2}-1\right)$ on $u=0, v>0$.

$$
T^{-1}\left(i \beta_{k}\right)=C_{k}=1-\frac{1}{k^{2}} .
$$

If we show that $\underline{\lim }_{k \rightarrow \infty}\left|\pi_{1}\left(i \beta_{k}\right)\right| \geqq \delta>0$, this implies

$$
\lim _{k \rightarrow \infty}\left|B_{1}\left(1-\frac{1}{k^{2}}\right)\right| \geqq \delta>0 \text {. }
$$

However, we know $\rho\left(C_{k}, C_{k+1}\right)$ tends to zero as $k \rightarrow \infty$. Thus by Theorem 3 , if $\left\{t_{k}\right\}$ is any real increasing sequence $t_{k}<1, t_{k} \rightarrow 1$ with $B_{1}\left(t_{k}\right) \rightarrow \alpha$, then we can choose a subsequence $\left\{C_{n_{k}}\right\}$ such that

$$
C_{n_{k}} \leqq t_{k}<C_{n_{k}+1}, \quad \rho\left(C_{n_{k}}, t_{k}\right)<\rho\left(C_{n_{k}}, C_{n_{k}+1}\right) .
$$

This implies $B_{1}\left(C_{n_{k}}\right) \rightarrow \alpha$ and so $|\alpha| \geqq \delta$. This proves $\underline{\lim }_{x \rightarrow 1}\left|B_{1}(x)\right|$ is positive. It remains to prove $\underline{\lim }_{k \rightarrow \infty}\left|\pi_{1}\left(i \beta_{k}\right)\right| \geqq \delta$.

The calculation for $\pi_{1}(\omega)$ is as follows:

$$
\begin{aligned}
\left|\pi_{1}\left(i \beta_{k}\right)\right|^{2} & =\prod_{n=1}^{\infty}\left|\frac{\beta_{k} e^{i(\pi / 2)}-\alpha_{n} e^{i(\pi / 4)}}{\alpha_{n} e^{-i(\pi / 4)}-\beta_{k} e^{i(\pi / 2)}}\right| \\
& =\prod_{n=1}^{\infty}\left(1-\frac{2 \sqrt{2} a_{n} \beta_{k}}{\alpha_{n}^{2}+\beta_{k}^{2}+\sqrt{2} \alpha_{n} \beta_{k}}\right) .
\end{aligned}
$$


Consider the following function of the positive real variables $\xi$ and $\eta$,

$$
g(\xi, \eta)=\frac{2 \sqrt{2}\left(2 e^{\xi}-1\right)\left(2 \eta^{2}-1\right)}{\left(2 e^{\xi}-1\right)^{2}+\left(2 \eta^{2}-1\right)^{2}+\sqrt{2}\left(2 e^{\xi}-1\right)\left(2 \eta^{2}-1\right)} .
$$

Setting $x=\left[\left(2 e^{\xi}-1\right) / 2 \eta^{2}-1\right]^{2}$ we have

$$
g(\xi, \eta)=\frac{2 \sqrt{2}}{x+\frac{1}{x}+\sqrt{2}} \leqq \frac{2 \sqrt{2}}{2+\sqrt{2}}<1
$$

since $x+(1 / x) \geqq 2$ if $x>0$.

We are considering the product $\prod_{n=1}^{\infty}(1-g(n, k))$, where $0 \leqq$ $g(n, k) \leqq \sigma<1$. We can choose a positive number $A$ so large that $1+x \geqq e^{A x}$ for $-\sigma \leqq x \leqq 0$. The number $A=-\log (1-\sigma) / \sigma$ will suffice $(A \geqq 2)$.

For each positive integer $k$ let $N(k)=N$ be the positive integer satisfying $N<2 \log k \leqq N+1 . \quad g(y, k)$ is monotone increasing on $1 \leqq y<2 \log k$ and monotone descreasing on $y>2 \log k$, with

$$
g(2 \log k, k)=\frac{1}{2\left(2 k^{2}-1\right)} .
$$

Thus we have for fixed $k$

$$
\begin{aligned}
\sum_{n=1}^{\infty} g(n, k) \leqq & 2 \sqrt{2}\left(2 k^{2}-1\right) \sum_{n=1}^{\infty} \frac{\left(2 e^{n}-1\right)}{\left(2 e^{n}-1\right)^{2}+\left(2 k^{2}-1\right)^{2}} \\
\leqq & 2 \sqrt{2}\left(2 k^{2}-1\right)\left[\int_{1}^{N} \frac{\left(2 e^{y}-1\right) d y}{\left(2 e^{y}-1\right)^{2}+\left(2 k^{2}-1\right)^{2}}\right. \\
& +\int_{N+1}^{\infty} \frac{\left(2 e^{y}-1\right) d y}{\left(2 e^{y}-1\right)^{2}+\left(2 k^{2}-1\right)^{2}} \\
& \left.+\frac{\left(2 e^{N}-1\right)}{\left(2 e^{N}-1\right)^{2}+\left(2 k^{2}-1\right)^{2}}+\frac{\left(2 e^{N+1}-1\right)}{\left(2 e^{N+1}-1\right)^{2}+\left(2 k^{2}-1\right)^{2}}\right] \\
\leqq & 2 \sqrt{2}\left(2 k^{2}-1\right)\left[\int_{1}^{\infty} \frac{\left(2 e^{y}\right) d y}{\left(2 e^{y}-1\right)^{2}+\left(2 k^{2}-1\right)^{2}}+\frac{2}{2\left(2 k^{2}-1\right)}\right] \\
= & \left.2 \sqrt{2} \arctan \left(\frac{2 e^{y}-1}{2 k^{2}-1}\right)\right|_{1} ^{\infty}+2 \sqrt{2} .
\end{aligned}
$$

Now evaluating the infinite product using the above estimates, we obtain

$$
\begin{aligned}
\prod_{n=1}^{\infty}(1-g(n, k)) & >\exp \left(-A \sum_{n=1}^{\infty} g(n, k)\right) \\
& \geqq \exp \left(-2 \sqrt{2} A\left(\frac{\pi}{2}-\arctan \left(\frac{2 e-1}{2 k^{2}-1}\right)\right)-2 \sqrt{2} A\right) .
\end{aligned}
$$

Thus $\underline{\lim }_{k \rightarrow \infty}\left|\pi_{1}\left(i \beta_{k}\right)\right|$ is positive. This completes the construction. 
The function $F(z)=B_{1}(z) / B_{2}(z)$ tends to $\infty$ on the real axis as $x \rightarrow 1$ and has a sequence of zeros on the nontangential curve (hyper(cycle) $h_{\alpha}$. Thus $F$ is not normal.

\section{BIBLIOGRAPHY}

1. F. Bagemihl, and W. Seidel, Sequential and continuous limits of meromorphic functions, Ann. Acad. Sci. Fenn. AI 280 (1960), 1-17.

2. O. Lehto, and K. I. Virtanen, Boundary behavior and normal meromorphic functions, Acta Math. 97 (1957), 47-65.

3. R. Nevanlinna, Eindeutige Analytische Funktionen, 2nd ed. Berlin, Gottingen, Heidelberg, 1953.

4. K. Noshiro, Contributions to the theory of meromorphic functions in the unit-circle, Journal of the Faculty of Science, Hokkaido Imperial University, Series 1, 7 (1939). 5. W Seidel, and J. L. Walsh, On the derivatives of functions analytic in the unit circle and their radii of univalence and of p-valence, Trans. Amer. Math. Soc. 52 (1942), 128-216. 



\section{PACIFIC JOURNAL OF MATHEMATICS}

\section{EDITORS}

\author{
H. Samelson \\ Stanford University \\ Stanford, California \\ R. M. Blumenthal \\ University of Washington \\ Seattle, Washington 98105
}

\author{
J. Dugundu \\ University of Southern California \\ Los Angeles, California 90007 \\ *Richard Arens \\ University of California \\ Los Angeles, California 90024
}

\section{ASSOCIATE EDITORS}
E. F. BeCKENBACH
B. H. NeUMANN
F. WOLF
K. YosidA

\section{SUPPORTING INSTITUTIONS}

\author{
UNIVERSITY OF BRITISH COLUMBIA \\ CALIFORNIA INSTITUTE OF TECHNOLOGY \\ UNIVERSITY OF CALIFORNIA \\ MONTANA STATE UNIVERSITY \\ UNIVERSITY OF NEVADA \\ NEW MEXICO STATE UNIVERSITY \\ OREGON STATE UNIVERSITY \\ UNIVERSITY OF OREGON \\ OSAKA UNIVERSITY \\ UNIVERSITY OF SOUTHERN CALIFORNIA
}

\author{
STANFORD UNIVERSITY \\ UNIVERSITY OF TOKYO \\ UNIVERSITY OF UTAH \\ WASHINGTON STATE UNIVERSITY \\ UNIVERSITY OF WASHINGTON \\ * * * * \\ AMERICAN MATHEMATICAL SOCIETY \\ CALIFORNIA RESEARCH CORPORATION \\ SPACE TECHNOLOGY LABORATORIES \\ NAVAL ORDNANCE TEST STATION
}

Mathematical papers intended for publication in the Pacific Journal of Mathematics should by typewritten (double spaced). The first paragraph or two must be capable of being used separately as a synopsis of the entire paper. It should not contain references to the bibliography. No separate author's resumé is required. Manuscripts may be sent to any one of the four editors. All other communications to the editors should be addressed to the managing editor, Richard Arens, at the University of California, Los Angeles, California 90024.

50 reprints per author of each article are furnished free of charge; additional copies may be obtained at cost in multiples of 50 .

The Pacific Journal of Mathematics is published quarterly, in March, June, September, and December. Effective with Volume 13 the price per volume (4 numbers) is $\$ 18.00$; single issues, $\$ 5.00$. Special price for current issues to individual faculty members of supporting institutions and to individual members of the American Mathematical Society: $\$ 8.00$ per volume; single issues $\$ 2.50$. Back numbers are available.

Subscriptions, orders for back numbers, and changes of address should be sent to Pacific Journal of Mathematics, 103 Highland Boulevard, Berkeley 8, California.

Printed at Kokusai Bunken Insatsusha (International Academic Printing Co., Ltd.), No. 6, 2-chome, Fujimi-cho, Chiyoda-ku, Tokyo, Japan.

PUBLISHED BY PACIFIC JOURNAL OF MATHEMATICS, A NON-PROFIT CORPORATION

The Supporting Institutions listed above contribute to the cost of publication of this Journal, but they are not owners or publishers and have no responsibility for its content or policies.

* Basil Gordon, Acting Managing Editor until February 1, 1966. 


\section{Pacific Journal of Mathematics}

\section{Vol. 15, No. $3 \quad$ November, 1965}

David R. Arterburn and Robert James Whitley, Projections in the space of

bounded linear operators .................................

Robert McCallum Blumenthal, Joram Lindenstrauss and Robert Ralph Phelps,

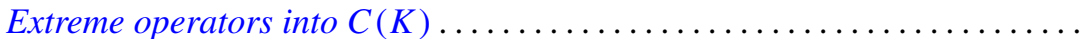

L. Carlitz, A note on multiple exponential sums ................... 757

Joseph A. Cima, A nonnormal Blaschke-quotient .................... 767

Paul Civin and Bertram Yood, Lie and Jordan structures in Banach algebras . . . 775

Luther Elic Claborn, Dedekind domains: Overrings and semi-prime

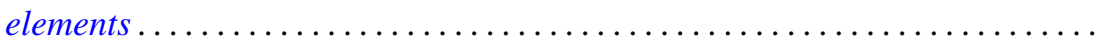

799

Luther Elic Claborn, Note generalizing a result of Samuel's .............. 805

George Bernard Dantzig, E. Eisenberg and Richard Warren Cottle, Symmetric

dual nonlinear programs ................................... 809

Philip J. Davis, Simple quadratures in the complex plane ............... 813

Edward Richard Fadell, On a coincidence theorem of F. B. Fuller ............ 825

Delbert Ray Fulkerson and Oliver Gross, Incidence matrices and interval

graphs ........................................ 835

Larry Charles Grove, Tensor products over $H^{*}$-algebras ..................

Deborah Tepper Haimo, $L^{2}$ expansions in terms of generalized heat polynomials

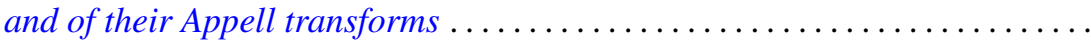

I. Martin (Irving) Isaacs and Donald Steven Passman, A chardcterization of groups in terms of the degrees of their characters ..........

Donald Gordon James, Integral invariants for vectors over local fields........ 905

Fred Krakowski, A remark on the lemma of Gauss ................... 917

Marvin David Marcus and H. Minc, A subdeterminant inequality ........... 921

Kevin Mor McCrimmon, Norms and noncommutative Jordan algebras ........ 925

Donald Earl Myers, Topologies for Laplace transform spaces ............... 957

Olav Njstad, On some classes of nearly open sets .................... 961

Milton Philip Olson, A characterization of conditional probability ........... 971

Barbara Osofsky, A counter-example to a lemma of Skornjakov .............. 985

Sidney Charles Port, Ratio limit theorems for Markov chains ............... 989

George A. Reid, A generalisation of $W^{*}$-algebras ...................... 1019

Robert Wells Ritchie, Classes of recursive functions based on Ackermann's

function ........................................... 1027

Thomas Lawrence Sherman, Properties of solutions of $n$th order linear

differential equations ........................................ 1045

Ernst Snapper, Inflation and deflation for all dimensions . .............. 1061

Kondagunta Sundaresan, On the strict and uniform convexity of certain Banach

spaces............................................. 1083

Frank J. Wagner, Maximal convex filters in a locally convex space .......... 1087

Joseph Albert Wolf, Translation-invariant function algebras on compact 